\title{
TGF- $\beta$ induces growth suppression in multiple myeloma MM.1S cells via E2F1
}

\author{
XIALEI LIU ${ }^{1}$, HUI GUO ${ }^{2}$, YUTING WEI ${ }^{3}$, CHAONONG CAI ${ }^{1}$, BAIMENG ZHANG ${ }^{1}$ and JIAN LI $^{1}$ \\ Departments of ${ }^{1}$ General Surgery $3,{ }^{2}$ Ultrasound and ${ }^{3}$ Hemodialysis, The Fifth Affiliated Hospital of Sun Yat-sen University, \\ Zhuhai, Guangdong 519000, P.R. China
}

Received November 3, 2015; Accepted April 13, 2017

DOI: $10.3892 / 01.2017 .6360$

\begin{abstract}
Transforming growth factor- $\beta$ (TGF- $\beta$ ) has an important role in multiple target genes and signaling pathways. The E2F family of transcription factors is a group of DNA-binding proteins that are involved in cell-cycle progression, and therefore have a key role in proliferation. The present study demonstrates that inhibition of cell growth by TGF- $\beta$ occurs in the multiple myeloma cell line MM.1S. However, the growth-suppressive effects of TGF- $\beta$ may be reversed by small interfering (si)RNA to reduce the expression of E2F1. TGF- $\beta 1$ and E2F1 siRNA were manipulated in MM.1S cells to investigate the association between these genes. FACScan Flow Cytometer, western blot analysis and other methods were adopted to confirm such interrelation. The present data showed that TGF- $\beta$ mediated growth suppression in MM.1S cells, while inducing E2F1 protein expression levels rapidly and transiently. The present data support the hypothesis that E2F1 is a central mediator of TGF- $\beta$-induced growth suppression in MM.1S cells and control of E2F1 may be a downstream event of TGF- $\beta$ action, at least in one multiple myeloma cell line.
\end{abstract}

\section{Introduction}

Transforming growth factor- $\beta$ (TGF- $\beta$ ) has an important role in essential cell phenotypes, particularly in cell proliferation, differentiation and apoptosis. Paradoxically, TGF- $\beta$ can be either a tumor suppressor or a tumor promoter, depending on the cell context and tissue (1). The canonical signaling pathway activated by TGF- $\beta$ is the SMAD pathway (2). It is also involved in other signaling pathways, including the

Correspondence to: Dr Jian Li, Department of General Surgery 3, The Fifth Affiliated Hospital of Sun Yat-sen University, 52 Meihua East Road, Zhuhai, Guangdong 519000, P.R. China

E-mail: 13798951969@163.com

Abbreviations: TGF- $\beta$, transforming growth factor- $\beta$; $\mathrm{pRb}$, retinoblastoma tumor-suppressor protein; $\mathrm{CDK}$, cyclin-dependent kinase

Key words: E2F1, MM.1S cell line, siRNA, TGF- $\beta$, cell viability mitogen-activated protein kinase, protein kinase $\mathrm{B}$, mammalian target of rapamycin and nuclear factor- $\kappa \mathrm{B}$ signaling pathways (3). However, the downstream mechanisms of TGF- $\beta$ that induce cell growth suppression have not been verified yet.

The E2F family of transcription factors is a group of DNA-binding proteins that are involved in cell-cycle progression, and therefore play a key role in cell proliferation (4). E2F1has a more pivotal role than other E2Fs, due to its unique character of inducing both cell-cycle progression and apoptosis (5). The transcriptional activity of E2F1 is regulated through the association with retinoblastoma tumor-suppressor protein (pRb) (6). Certain studies have reported that TGF- $\beta$ regulates the transcription of a number of pro-apoptotic genes in an E2F1-dependent manner in cancer cell lines from various tissues (7). To investigate whether E2F1 could also mediate the TGF- $\beta$-induced cytostatic response in multiple myeloma cells, the MM.1S cell line was used in the present study.

The present study found that cell proliferation was markedly inhibited in TGF- $\beta$-treated MM.1S cells, and this process was reversed subsequent to anti-E2F1siRNA treatment. The present data support the conclusion that E2F1 is a central mediator of the TGF- $\beta$ induced growth arrest, at least in one of the multiple myeloma cell lines.

\section{Materials and methods}

Cell lines, reagents, treatments and transfection. Human myeloma MM.1S cells were obtained from American Type Culture Collection (Manassas, VA, USA). The multiple myeloma cells were maintained in RPMI-1640 medium (Invitrogen; Thermo Fisher Scientific, Inc., Waltham, MA, USA) supplemented with $10 \%$ fetal bovine serum (FBS) (HyClone; GE Healthcare Life Sciences, Logan, UT, USA), $50 \mathrm{U} / \mathrm{ml}$ penicillin and streptomycin, and cells were grown at $37^{\circ} \mathrm{C}$ in a $5 \% \mathrm{CO}_{2}$ atmosphere. All TGF- $\beta$ treatments were performed in serum-free medium with or without $5 \mathrm{ng} / \mathrm{ml}$ TGF- $\beta 1$ (PeproTech, Rocky Hill, NJ, USA) to cells which were serum-starved for $24 \mathrm{~h}$. A total of $10^{5}$ cells per well were seeded into a 6-well cell culture plate in $2 \mathrm{ml}$ of antibiotic-free normal growth medium supplemented with FBS. Cells were transiently transfected with siRNAs against E2F1 (cat. no. sc-29297) or control siRNA (cat. no. sc-37007; both from Santa Cruz Biotechnology, Inc., Dallas, TX, USA), according to the manufacturer's instructions. 
Cell viability assays. The MM.1S cells were seeded in 96-well plates at a density of 10,000 cells per well. After 24,48 or $72 \mathrm{~h}$, cell viability was determined by assaying with MTS assay (Promega Corp., Madison, WI, USA). The MTS assay was performed according to the manufacturer's instructions. Absorbance was measured at $490 \mathrm{~nm}$ with a Chameleon plate reader (Bioscan, Inc., Poway, CA, USA).

Cell cycle analysis. In total, $10^{4}$ cells from each group were seeded into a 6-well culture plate. Cells were then harvested subsequent to culture for $72 \mathrm{~h}$ and fixed in $80 \%$ ethanol. The fixed cells were stained with propidium iodide (PI). The cell cycle distribution analysis was performed by FACS can Flow Cytometer (BD Biosciences, Franklin Lakes, NJ, USA) and analyzed by the CellQuest software package. Each procedure was repeated three times.

Western blot analysis. Cells were washed with ice-cold phosphate-buffered saline, and total proteins were isolated using radioimmunoprecipitation assay lysis buffer, which included protease inhibitors (leupeptin, antipain and aprotinin), $0.5 \mathrm{mM}$ PMSF and $0.2 \mathrm{mM}$ sodium orthovanadate (Thermo Fisher Scientific, Inc.). Protein amounts were quantified by the Bradford Protein Assay (Bio-Rad Laboratories, Inc., Hercules, CA, USA). Equal amounts of proteins were loaded and separated on Criterion ${ }^{\mathrm{TM}}$ Tris- $\mathrm{HCl}$ Precast Gels (Bio-Rad Laboratories, Inc., Hercules, CA, USA), transferred onto polyvinylidene fluoride membranes, and probed with the appropriate antibody, as follows: Rabbit polyclonal anti-E2F1 (cat. no. 3742; dilution, 1:1,000) or anti-phospho-pRb (cat. no. 9308; dilution, 1:1,000) (Cell Signaling Technology, Danvers, MA, USA). The antibody was added for an overnight incubation at $4^{\circ} \mathrm{C}$. Membranes were then washed, incubated with horseradish peroxidase-conjugated goat anti-rabbit immunoglobulin (cat. no. P0448; dilution, 1:2,000; Dako; Agilent Technologies, Inc., Santa Clara, CA, USA), and developed with SuperSignal chemiluminescent substrate (Pierce; Thermo Fisher Scientific, Inc.).

Statistical analysis. The results are expressed as the mean \pm standard deviation. Subsequent to identifying a normal distribution, data were compared using Student's t-test. $\mathrm{P}<0.05$ was considered to indicate a statistically significant difference. Bonferroni correction was adopted as the post-hoc test used to control for multiple comparisons with the same control.

\section{Results}

TGF- $\beta$-mediated growth suppression in MM.1S cells. MM.1S cells were grown in the presence or absence of TGF- $\beta$, as indicated, and cell viability was assessed using a MTS assay. It was found that growth of MM.1S cells was inhibited by TGF- $\beta$ in a time-dependent manner $(\mathrm{P}<0.05$; Fig. $1 \mathrm{~A})$. This was confirmed by a reduction in cell count $(\mathrm{P}<0.05$; Fig. $1 \mathrm{~B})$. MM.1S cells were seeded overnight at $3 \times 10^{5} / \mathrm{ml}$, during which time almost $60 \%$ of cells were synchronized in the G1 phase of the cell cycle, as measured by PI staining (Fig. 1C). Cells were then stimulated or not with TGF- $\beta$ for $48 \mathrm{~h}$. Control cells progressed from G1 to $\mathrm{S}$ phase through the cell cycle, whereas

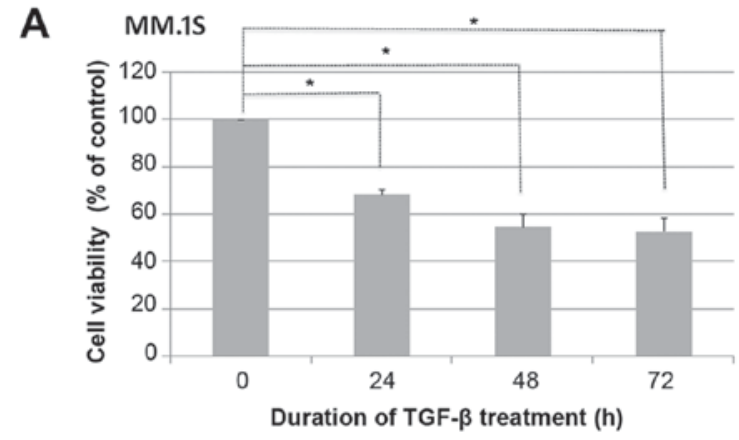

B
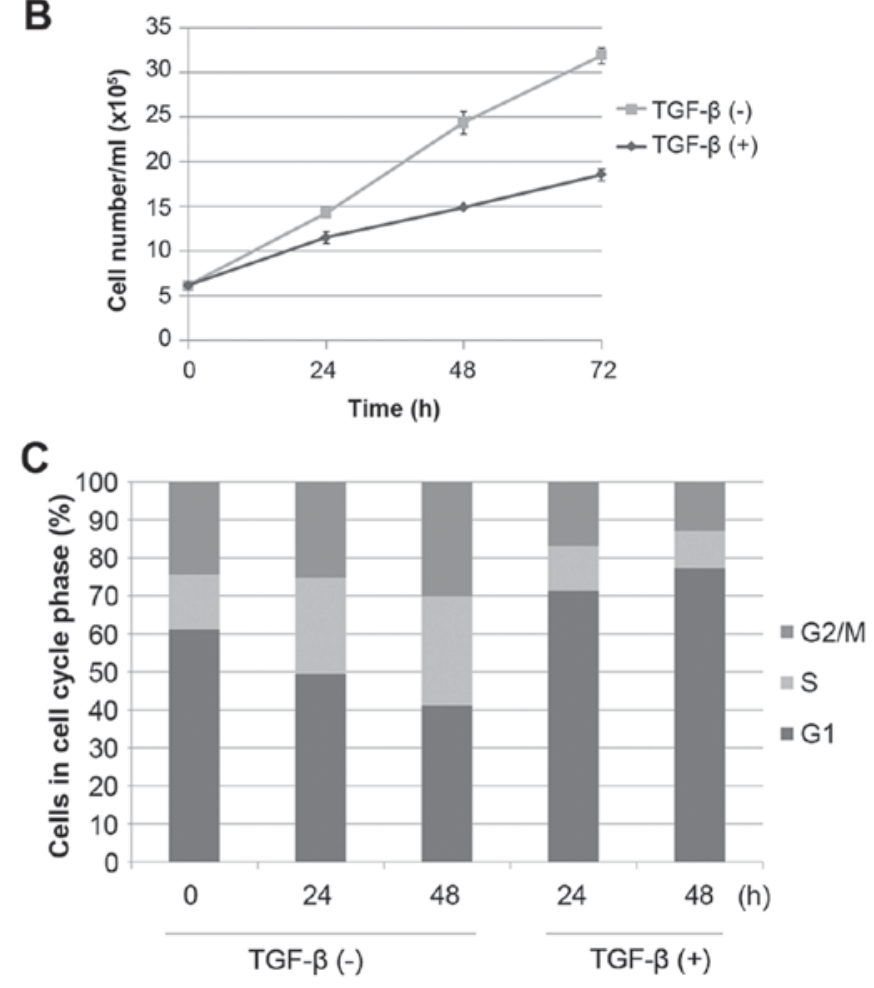

Figure 1.TGF- $\beta$ induces efficient G1 cell cycle suppression in MM.1S cells. (A) The MM.1S cell lines were either left untreated or treated with $5 \mathrm{ng} / \mathrm{ml} \mathrm{TGF}-\beta$ for the indicated times and assessed for cell viability by MTS. (B) Cells were treated as aforementioned, and the cell count was determined at the indicated time points. Results are expressed as the mean \pm standard deviation of two independent experiments, with each performed in triplicate. (C) MM.1S cells were seeded at a density of $3 \times 10^{5}$ cells $/ \mathrm{ml}$ overnight, stained with propidium iodide, and analyzed by flow cytometry. Bar graphs show the percentage of MM.1S cells in each cell cycle phase for three independent experiments. TGF- $\beta$, transforming growth factor $-\beta$. ${ }^{*} \mathrm{P}<0.05$.

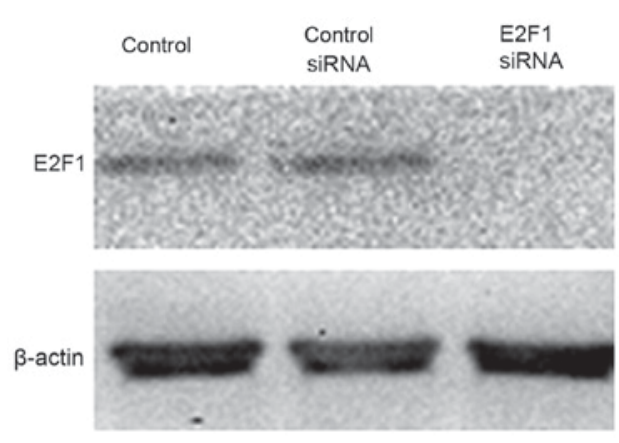

Figure 2. The efficiency of E2F1 knockdown by siRNA was verified by immunoblotting using an E2F1-specific antibody. Ctl, cells without transfection; siRNA, small interfering RNA; Ctl siRNA, cells transfected with unrelated siRNA controls; E2F1 siRNA, cells transfected with anti-E2F1 siRNA. 
A

$48 \mathrm{~h}$

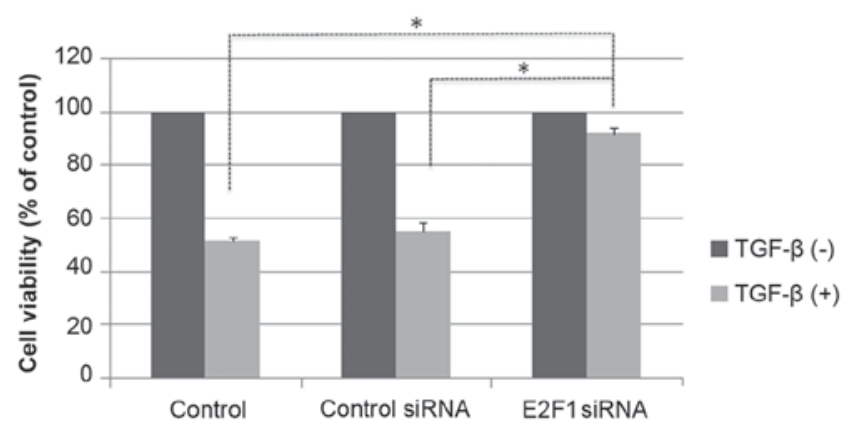

Treatment of control/control siRNA/siRNA (E2F1)
B

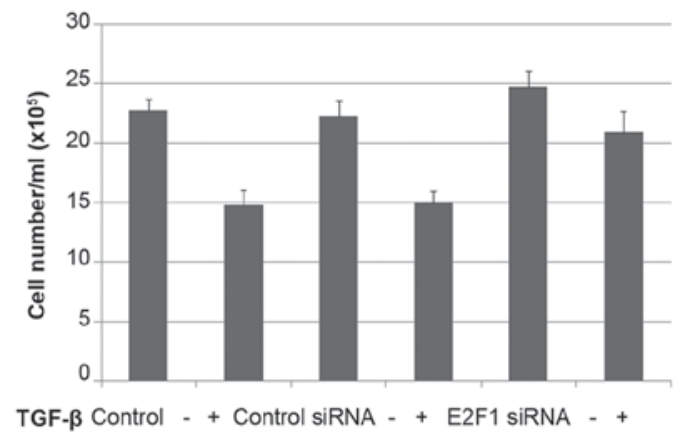

C

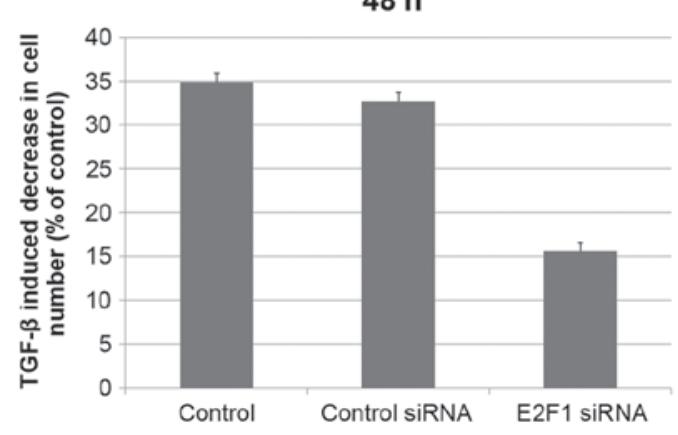

D

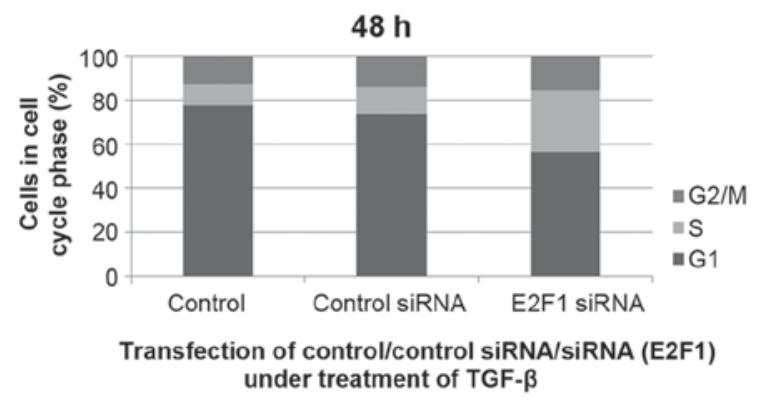

Figure 3. TGF- $\beta$-mediated cell growth suppression is impaired in E2F1-null MM.1S cells. (A) Cells without transfection, cells transfected with unrelated siRNA controls and cells transfected with anti-E2F1 siRNA were stimulated or not with TGF- $\beta$ for 48 h, and cell viability was assessed by MTS assay. (B) Cell numbers following $48 \mathrm{~h}$ of TGF- $\beta$ treatment. Cells were seeded overnight at $3 \times 10^{5} / \mathrm{ml}$ and treated with or without $5 \mathrm{ng} / \mathrm{ml}$ TGF- $\beta$ for experiment and analyzed as the mean \pm standard deviation. (C) Reduction in cell number induced by TGF- $\beta$ (expressed as a percentage of untreated control cultures) determined from three independent experiments $(n=3)$. (D) MM.1S cells without transfection, cells transfected with unrelated siRNA controls and cells transfected with anti-E2F1 siRNA were stimulated with TGF- $\beta$ for $48 \mathrm{~h}$, stained with propidium iodide, and analyzed by flow cytometry. Bar graphs show the percentage of MM.1S cells in each cell cycle phase for the average of three independent experiments. Ctl, cells without transfection; siRNA, small interfering RNA; Ctl siRNA, cells transfected with unrelated siRNA controls; E2F1 siRNA, cells transfected with anti-E2F1 siRNA; TGF- $\beta$, transforming growth factor- $\beta$. * $<0.05$.

TGF- $\beta$-treated cells exhibited efficient G1 cell cycle suppression $(\mathrm{P}<0.05$; Fig. $1 \mathrm{C})$.

E2F1 is required for TGF- $\beta$-mediated growth suppression. To study the contribution of E2F1 in mediating this TGF- $\beta$ response, RNA interference was used to reduce the expression of endogenous E2F1 (Fig. 2). It was found that the effect of TGF- $\beta$ on cell viability in the MM.1S cell lines tested was almost completely prevented when E2F1 expression was silenced, indicating that E2F1 is required for mediating the TGF- $\beta$-induced response in the multiple myeloma MM.1S cell line $(\mathrm{P}<0.05$; Fig. 3A). The cells transfected with anti-E2F1 siRNA had reduced TGF- $\beta$-mediated growth suppression in cell counting experiments $(\mathrm{P}<0.05$; Fig. $3 \mathrm{~B}$ and $\mathrm{C})$. The effect of anti-E2F1 siRNA on the MM.1S cell cycle was examined and each test was repeated three times. Fig. 3D showed the mean values of triplicate experiments. Compared with the control MM.1S cells, the percentage of G1 stage cells was reduced following transfection with siRNA E2F1 construct. Although the percentage of $\mathrm{S}$ stage cells was significantly increased, no significant change was identified in the proportion of G2/M stage cells.

$T G F-\beta$ induces E2F1 protein expression levels rapidly and transiently. To determine whether E2F1 expression itself is

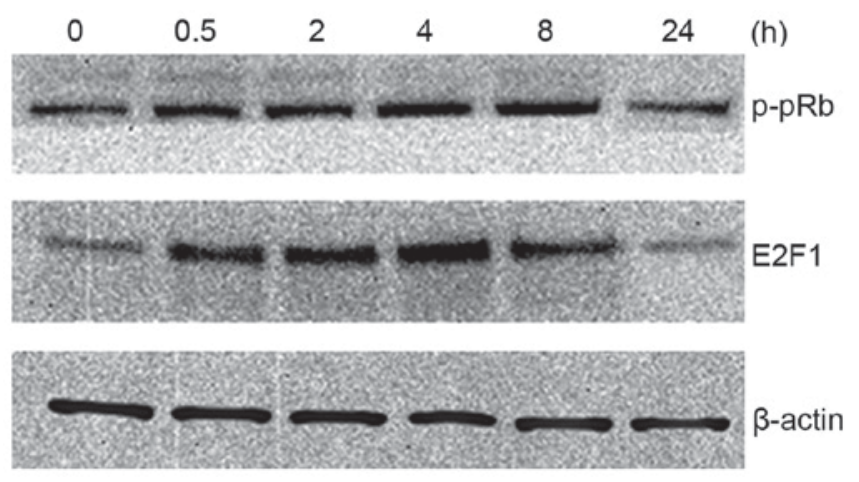

Figure 4. Western blot analysis of the phosphorylation state of $\mathrm{pRb}$ and total E2F1 protein levels in TGF- $\beta$-treated cells shows TGF- $\beta$ induces E2F1 protein expression levels transiently. TGF- $\beta$, transforming growth factor- $\beta$; $\mathrm{pRb}$, retinoblastoma tumor-suppressor protein.

regulated by TGF- $\beta$, the TGF- $\beta$ effect on E2F1 protein expression levels was examined in MM.1S cells. As shown in Fig. 4, E2F1 protein levels are induced by TGF- $\beta$. This effect was transient (within $4 \mathrm{~h}$ ); however, longer exposure to TGF- $\beta$ resulted in a return to basal E2F1 protein levels (within $24 \mathrm{~h}$ ). It was also found that the phosphorylation state of $\mathrm{pRb}$ showed a similar trend. 


\section{Discussion}

Although numerous cell proliferation mediators and signaling pathways have been implicated in TGF- $\beta$ mediated growth arrest, the majority of these mechanisms appear to be tissue-specific and cell type-dependent (8). Previous studies have indicated that the key event in TGF- $\beta$-mediated cytostatic responses in epithelial cells is c-myc and its target genes. TGF- $\beta$-mediated cytostasis is induced by Smad-dependent regulation of target genes involved in cell cycle control (9-11). Progression between G1 and S phase is dependent on cyclin-dependent kinases (CDKs), including CDK2, CDK4, CDK6, cyclin D and cyclin E $(9,10,12,13)$. The downregulation of c-myc prevents TGF- $\beta$ mediated cell cycle arrest (11). At present, evidence whether the mechanism is suitable for non-epithelial cells, such as hematological cells, is lacking (14). The present study analyzed the common multiple myeloma MM.1S cell line and defined a novel process of the TGF- $\beta$-E2F1 signaling axis, and identified E2F1 as a critical mediator of the TGF- $\beta$ proliferation inhibition program in multiple myeloma cells.

To examine the association between TGF- $\beta$, E2F1 expression and proliferation of MM.1S cells, the expression of E2F1 was inhibited by siRNA in MM.1S cells in the present study. The current study showed that TGF- $\beta$-induced growth suppression was reversed in MM.1S cells subsequent to transfection with anti-E2F1 siRNA. It demonstrated that E2F1 has an essential role in TGF- $\beta$ activity and cell proliferation in MM.1S cells.

The $\mathrm{pRb}$-E2F1 complex has been shown to be a suppressor of E2F target genes, with phosphorylation of $\mathrm{pRb}$ leading to disruption of the pRb-E2F1 complex, which is required to release free E2F1, in order to induce transcription of its target genes $(6,15,16)$. Loss of $\mathrm{pRb}$ function induces resistance to TGF- $\beta$ (17). It is also evident that E2F1 has an important role in cell growth control and regulation of G1 progression. The control of E2F1 activity may be a downstream event from the action of G1 CDKs. The growth-suppressing effects of TGF- $\beta$ coincide with the downregulation of G1 kinase activities and the concomitant conversion of $\mathrm{Rb}$ to the phosphorylated form $(17,18)$. Therefore, the E2F1 activity may be an important target of the TGF- $\beta$ growth-inhibitory signaling pathway. The present results support this model, since the TGF- $\beta$-mediated growth suppression can be overcome by reduced expression of the E2F1 product. In the present study, TGF- $\beta$ signaling rapidly induced phosphorylation of $\mathrm{pRb}$, and E2F1 protein levels strongly increased accordingly. However, the effect was transient, with both the p-pRb and E2F1 protein levels returning to the basal level within $24 \mathrm{~h}$. This supports the hypothesis that $\mathrm{E} 2 \mathrm{~F} 1$ activity is controlled through association with $\mathrm{pRb}$.

In multiple myeloma, TGF- $\beta$ is secreted by myeloma and bone marrow stromal cells $(19,20)$. TGF- $\beta$ is an important factor during the disease development, which involves a complex signaling pathway network. The canonical signaling SMAD $(21,22)$ pathway and the non-SMAD $(23-25)$ signaling pathways have been studied extensively. Numerous genes, including c-myc, CDK, p53 and numerous other inhibitors of DNA binding genes are described as key growth-promoting factors; however, E2F1is not (26). Spender and Inman (27) reported that downregulation of E2F1 is the predominant mechanism by which TGF- $\beta$ could induce cell cycle arrest in
Burkitt lymphoma cells. Korah et al (28) reported that E2F1 is central to TGF- $\beta$-mediated apoptosis. In the present study, it was found that the transcription factor E2F1 is involved, at least partially, in the TGF- $\beta$-induced growth arrest. However, the possibility that induction of other targets or pathways also contributes to TGF- $\beta$-mediated cell growth arrest cannot be excluded. The possible mechanisms are independent of other well-established genes and are likely to have occurred downstream of known signaling pathways. The present data support the notion that E2F1 is a central mediator of TGF- $\beta$ induced growth suppression in MM.1S cells. An improved understanding of the mechanisms by which both TGF- $\beta$ and E2F1 exert their roles maybe useful for the identification of therapeutic strategies in multiple myeloma.

\section{Acknowledgements}

The authors thank Dr Baimeng Zhang (Department of Hepatobiliary Surgery, The Fifth Hospital of Sun Yat-Sen University) for useful discussions. The present study received financial support from The Fifth Affiliated Hospital of Sun Yat-sen University Grants Commission (grant no. 2009058) and infrastructural support from the Department of General Surgery, The Fifth Affiliated Hospital of Sun Yat-sen University.

\section{References}

1. Derynck R and Akhurst RJ: Differentiation plasticity regulated by TGF-beta family proteins in development and disease. Nat Cell Biol 9: 1000-1004, 2007.

2. Chen YG: Endocytic regulation of TGF-beta signaling. Cell Res 19: 58-70, 2009.

3. Moustakas A and Heldin CH: Non-Smad TGF-beta signals. J Cell Sci 118: 3573-3584, 2005.

4. Bell LA and Ryan KM: Life and death decisions by E2F-1. Cell Death Differ 11: 137-142, 2004

5. Field SJ, Tsai FY, Kuo F, Zubiaga AM, Kaelin WG Jr, Livingston DM, Orkin SH and Greenberg ME: E2F-1 functions in mice to promote apoptosis and suppress proliferation. Cell 85: 549-561, 1996.

6. Dyson N: The regulation of E2F by pRB-family proteins. Genes Dev 12: 2245-2262, 1998

7. Sherr CJ and McCormick F: The RB and $\mathrm{p} 53$ pathways in cancer. Cancer Cell 2: 103-112, 2002.

8. Pardali K and Moustakas A: Actions of TGF-beta as tumor suppressor and pro-metastatic factor in human cancer. Biochim Biophys Acta 1775: 21-62, 2007.

9. Siegel PM and Massagué J: Cytostatic and apoptotic actions of TGF-beta in homeostasis and cancer. Nat Rev Cancer 3: 807-821, 2003.

10. Chen CR, Kang Y and Massagué J: Defective repression of c-myc in breast cancer cells: A loss at the core of the transforming growth factor beta growth arrest program. Proc Natl Acad Sci USA 98: 992-999, 2001.

11. Warner BJ, Blain SW, Seoane J and Massagué J: Myc downregulation by transforming growth factor beta required for activation of the p15(Ink4b) G(1) arrest pathway. Mol Cell Biol 19: 5913-5922, 1999.

12. Iavarone A and Massagué J: Repression of the CDK activator Cdc25A and cell-cycle arrest by cytokine TGF-beta in cells lacking the CDK inhibitor p15. Nature 387: 417-422, 1997.

13. Baughn LB, Di Liberto M, Niesvizky R, Cho HJ, Jayabalan D, Lane J, Liu F and Chen-Kiang S: CDK2 phosphorylation of Smad2 disrupts TGF-beta transcriptional regulation in resistant primary bone marrow myeloma cells. J Immunol 182: 1810-1817, 2009.

14. Molina-Privado I, Rodríguez-Martínez M, Rebollo P, MartínPérez D, Artiga MJ, Menárguez J, Flemington EK, Piris MA and Campanero MR: E2F1 expression is deregulated and plays an oncogenic role in sporadic Burkitt's lymphoma. Cancer Res 69: 4052-4058, 2009. 
15. Hallstrom TC, Mori S and Nevins JR: An E2F1-dependent gene expression program that determines the balance between proliferation and cell death. Cancer Cell 13: 11-22, 2008.

16. Sun B, Wingate H, Swisher SG, Keyomarsi K and Hunt KK: Absence of $\mathrm{pRb}$ facilitates E2F1-induced apoptosis in breast cancer cells. Cell Cycle 9: 1122-1130, 2010.

17. Schwarz JK, Bassing CH, Kovesdi I, Datto MB, Blazing M, George S, Wang XF and Nevins JR: Expression of the E2F1 transcription factor overcomes type beta transforming growth factor-mediated growth suppression. Proc Natl Acad Sci USA 92: 483-487, 1995

18. Chellappan SP, Hiebert S, Mudryj M, Horowitz JM and Nevins JR: The E2F transcription factor is a cellular target for the RB protein. Cell 65: 1053-1061, 1991.

19. Mohammad KS, Chen CG, Balooch G, Stebbins E, McKenna CR, Davis H, Niewolna M, Peng XH, Nguyen DH, Ionova-Martin SS, et al: Pharmacologic inhibition of the TGF-beta type I receptor kinase has anabolic and anti-catabolic effects on bone. PLoS One 4: e5275, 2009.

20. Matsumoto T and Abe M: TGF- $\beta$-related mechanisms of bone destruction in multiple myeloma. Bone 48: 129-134, 2001.

21. Hayashi H, Abdollah S, Qiu Y, Cai J, Xu YY, Grinnell BW, Richardson MA, Topper JN, Gimbrone MA Jr, Wrana JL and Falb D: The MAD-related protein Smad7 associates with the TGFbeta receptor and functions as an antagonist of TGFbeta signaling. Cell 89: 1165-1173, 1997.
22. Hata A, Lagna G, Massagué J and Hemmati-Brivanlou A: Smad6 inhibits BMP/Smad1 signaling by specifically competing with the Smad4 tumor suppressor. Genes Dev 12: 186-197, 1998.

23. Bakin AV, Rinehart C, Tomlinson AK and Arteaga CL: p38 mitogen-activated protein kinase is required for TGFbetamediated fibroblastic transdifferentiation and cell migration. J Cell Sci 115: 3193-3206, 2002.

24. Bakin AV, Tomlinson AK, Bhowmick NA, Moses HL and Arteaga CL: Phosphatidylinositol 3-kinase function is required for transforming growth factor beta-mediated epithelial to mesenchymal transition and cell migration. J Biol Chem 275: 36803-36810, 2000.

25. Bhowmick NA, Ghiassi M, Bakin A, Aakre M, Lundquist CA, Engel ME, Arteaga CL and Moses HL: Transforming growth factor-betal mediates epithelial to mesenchymal transdifferentiationthrough a RhoA-dependent mechanism. Mol Biol Cell 12: 27-36, 2001.

26. Siegel PM and Massagué J: Cytostatic and apoptotic actions of TGF-beta in homeostasis and cancer. Nat Rev Cancer 3: 807-821, 2003.

27. Spender LC and Inman GJ: TGF-beta induces growth arrest in Burkitt lymphoma cells via transcriptional repression of E2F-1. J Biol Chem 284: 1435-1442, 2009.

28. Korah J, Falah N, Lacerte A and Lebrun JJ: A transcriptionally active pRb-E2F1-P/CAF signaling pathway is central to TGFß-mediated apoptosis. Cell Death Dis 3: e407, 2012. 